\title{
PHOSPHORYLASE ACTIVITY IN RAT UTERUS AFTER CATECHOLAMINE ADMINISTRATION*
}

\author{
Jack Diamond and Theodore M. Brody \\ Department of Pharmacology, University of Michigan Medical School, \\ Ann Arbor, Mich., U.S.A.
}

(Received 29 May 1964; accepted 21 September 1964)

\begin{abstract}
The effects of epinephrine, norepinephrine, and isoproterenol on uterine phosphorylase were studied in intact, anesthetized rats. All three agents were found to increase uterine phosphorylase $a$ activity when administered in large doses by intraperitoneal injection. Total phosphorylase activity was unaffected. The time course for the effects of epinephrine on uterine phosphorylase activity and glycogen content was also studied. Peak phosphorylase activation occurred within $5 \mathrm{~min}$ after injection, and the effect had disappeared within $1 \mathrm{hr}$. Increase in phosphorylase $a$ activity was accompanied by a decrease in uterine glycogen levels, which were still depressed at a time when phosphorylase $a$ activity had returned to normal.

Epinephrine was shown to stimulate phosphorylase $a$ activity in the uteri of ovariectomized and estrogen-primed rats as well as in normal intact animals. Ovariectomized animals treated with estradiol had higher resting phosphorylase $a$ activity than had normal untreated animals.

The relative ability of several adrenergic blocking agents to prevent catecholamineinduced increases in uterine phosphorylase $a$ activity was investigated, It was suggested that the catecholamines produced their effects on the uterus both directly, via $\beta$-adrenergic stimulation, and indirectly, via ischemia and resultant tissue anoxia induced by activation of $a$-adrenergic receptors in the uterine vasculature.

The ability of epinephrine to activate uterine phosphorylase when administered by intravenous infusion was also demonstrated.
\end{abstract}

THE activation of glycogen phosphorylase by catecholamines has been demonstrated in many tissues, including heart, skeletal muscle, and liver (see reviews by Ellis, 1 Stetten and Stetten, ${ }^{2}$ and Sutherland and Rall ${ }^{3}$ ). It has also been demonstrated that increases in phosphorylase activity are accompanied by decreases in glycogen content of the tissues. ${ }^{3-6}$ However, the effects of catecholamines on phosphorylase activity of smooth muscle have not been so well documented. Activation of phosphorylase by epinephrine has been reported in isolated strips of rabbit uterus ${ }^{7}$ but not in rat or guinea pig uterus or in rabbit intestinal strips., ${ }^{3,7}$ On the other hand, in a recent report Leonard and Crandall were able to show increases in phosphorylase $a$ in isolated segments of rat uterus after exposure to epinephrine. ${ }^{8}$ Bueding et al. have failed to demonstrate activation of phosphorylase by epinephrine in isolated strips of guinea pig Taenia coli. ${ }^{9}$

The only reports concerning the efforts of epinephrine on the activity of smooth muscle phosphorylase in vivo are those of Leonard, ${ }^{10,11}$ in which large doses of epinephrine (500 $\mu \mathrm{g} / \mathrm{kg}$, i.p.) were reported to decrease both phosphorylase $a$ and glycogen

* This study was supported in part by a contract between the University of Michigan and the Office of Naval Research, NONR-1224-27. 
content in the uteri of ovariectomized and estrogen-primed rats. The present results fail to support these findings with respect to phosphorylase activity after epinephrine. Data presented will show that, under conditions similar to those of Leonard, epinephrine produces an activation of uterine phosphorylase accompanied by a decrease in the glycogen content of that organ.

\section{METHODS}

White female rats of the Holtzman strain were used throughout this investigation. All animals weighed from 180 to $220 \mathrm{~g}$, with the exception of the ovariectomized estrogen-primed group, which weighed $275-300 \mathrm{~g}$ at the time of sacrifice. They received food and water $a d$ lib. at all times.

Commercial solutions of $l$-epinephrine (Adrenalin, Parke, Davis \& Co), l-norepinephrine (Levophed, Winthrop Laboratories) and $l$-isoproterenol (Isuprel, Winthrop Laboratories) were diluted in a solution of $0.9 \% \mathrm{NaCl}$ and $0.1 \% \mathrm{NaHSO}_{3}$ to obtain the proper concentration for injection. Dichloroisoproterenol (DCI) and 2isopropylamino-1-(2-naphthyl)-ethanol (nethalide) were injected s.c. in doses of 10 $\mathrm{mg} / \mathrm{kg}$ and $25 \mathrm{mg} / \mathrm{kg}$, respectively, $30 \mathrm{~min}$ before administration of catecholamines. Phenoxybenzamine (Dibenzyline, Smith, Kline \& French Laboratories), in a dose of $7 \mathrm{mg} / \mathrm{kg}$, was injected i.p. 2 to $3 \mathrm{hr}$ before catecholamine administration. Estradiol benzoate, dissolved in peanut oil, was administered s.c. in a dose of $50 \mu \mathrm{g} / \mathrm{rat}, 48 \mathrm{hr}$ before epinephrine injections.

Animals were anesthetized by the i.p. injection of hexobarbital sodium (150-180 $\mathrm{mg} / \mathrm{kg}$ ) $10 \mathrm{~min}$ before sacrifice. The uteri were quickly cleared of adhering fat, rapidly excised, and frozen in isopentane cooled in a mixture of alcohol and dry ice.

Glycogen was isolated according to the method of Hassid and Abraham ${ }^{12}$ and glucose determined with anthrone reagent. ${ }^{13}$ Glycogen values are expressed as milligrams of glycogen per gram wet weight of tissue.

Phosphorylase was determined by a modification of the method originally described by Cori and Cori. ${ }^{14}$ The liberation of inorganic phosphate during the synthesis of glycogen from glucose-1-phosphate was used as measure of phosphorylase activity. Uterine samples weighing from 50 to $100 \mathrm{mg}$ were homogenized (in a ground-glass homogenizer) in 100 volumes of a solution containing $0.05 \mathrm{M}$ Tris buffer (pH 6.8), $0.001 \mathrm{M}$ EDTA, $0.02 \mathrm{M} \mathrm{NaF}$, and $0.3 \%$ serum albumin. All procedures were carried out at $0^{\circ}-4^{\circ}$. After centrifugation of the homogenate at $10,000 \mathrm{~g}$ for $10 \mathrm{~min}, 0 \cdot 2-\mathrm{ml}$ aliquots of the supernatant were incubated for $30 \mathrm{~min}$ at $37.5^{\circ}$ in test tubes containing $0.05 \mathrm{M}$ Tris buffer (pH 6.8), 0.4\% glycogen, 0.01 M glucose-1-phosphate, $0.001 \mathrm{M}$ EDTA, $0.02 \mathrm{M} \mathrm{NaF}$, and $0.3 \%$ serum albumin, in a final volume of $1.0 \mathrm{ml}$. Duplicate samples of the supernatant solutions were incubated in the same reaction mixture containing, in addition, AMP in a final concentration of $0.001 \mathrm{M}$. The reaction was terminated by the addition of $2.0 \mathrm{ml}$ of $10 \%$ trichloroacetic acid. The samples were then centrifuged in the cold room at $2,500 \mathrm{~g}$ for $10 \mathrm{~min}$ and the supernatants assayed for inorganic phosphate by the method of Fiske and SubbaRow. 15

The rate of liberation of inorganic phosphate was linear over the time studied and was proportional to enzyme concentration. When the glycogen primer was omitted from the reaction mixture, the liberation of inorganic phosphate was negligible. Also, no phosphoglucomutase activity could be detected under the conditions of this 
assay. Phosphoglucomutase activity was determined by the method described by Cori, et al. ${ }^{16}$

The amount of inorganic phosphate liberated in the absence of AMP represented phosphorylase $a$, and the amount liberated in the presence of AMP was a measure of total phosphorylase. Results are reported as (phosphorylase a/total phosphorylase) $\times 100$.

\section{RESULTS}

Uterine phosphorylase activity and glycogen content after intraperitoneal administration of epinephrine

Figure 1 shows a time curve of the effects of epinephrine $(500 \mu \mathrm{g} / \mathrm{kg}$ i.p.) on the phosphorylase $a$ activity and glycogen content of rat uterus. Phosphorylase was

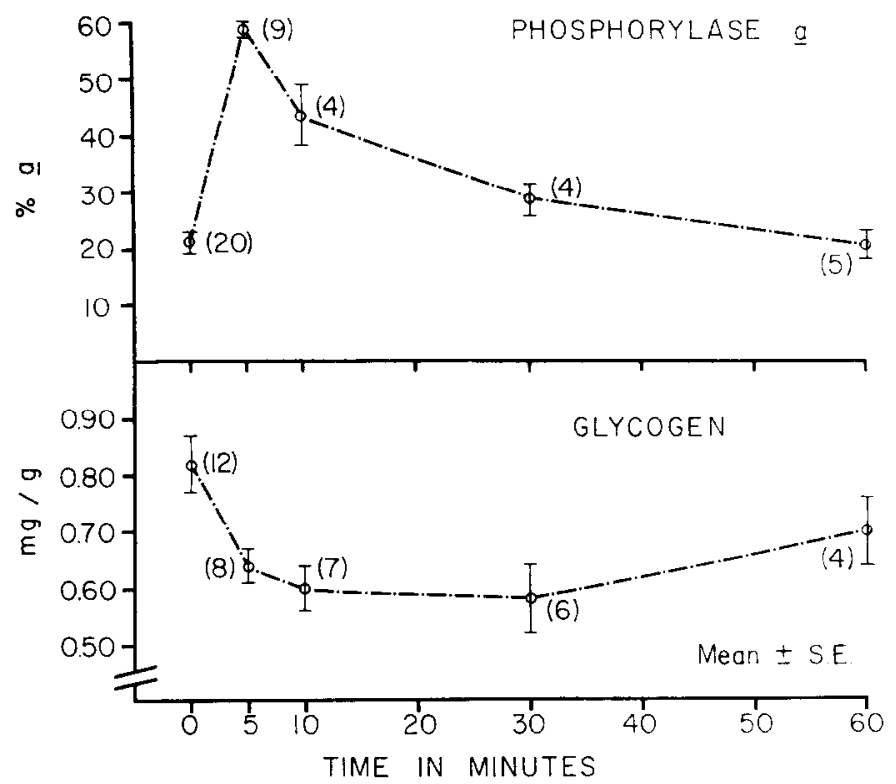

Fig. 1. Effect of epinephrine ( $500 \mu \mathrm{g} / \mathrm{kg}$ i.p.) on the per cent phosphorylase $a$ and glycogen content of rat uterus. In all graphs the figures in parentheses indicate the number of animals at each point. The phosphorylase $a$ values at 5,10 , and $30 \mathrm{~min}$ after injection are significantly higher than controls $(P<0.001$ to 0.05$)$. The glycogen content is significantly decreased at 5,10 , and 30 minutes $(P<0.01)$.

markedly activated $5 \mathrm{~min}$ after epinephrine administration and had returned to control levels within $1 \mathrm{hr}$ after injection of the drug. Glycogen decreased progressively until $30 \mathrm{~min}$ after injection and had not returned to normal within the 1-hr period studied.

The total amount of phosphorylase in the uterus was not significantly altered by epinephrine administration. When calculated on the basis of total enzyme per milligram wet weight of frozen tissue, it appeared that, not only had the per cent phosphorylase $a$ increased, but that total phosphorylase activity appeared to be greater as well. For example, $5 \mathrm{~min}$ after the dose of $500 \mu \mathrm{g}$ epinephrine $/ \mathrm{kg}$, phosphorylase $a$ (expressed as micromoles of inorganic phosphate liberated per $30 \mathrm{~min}$ 
per gram wet weight of tissue at $37.5^{\circ}$ ) had increased from $29.0 \pm 2.5$ (mean \pm standard error of 12 controls) to $114 \pm 4.5$ (mean \pm standard error of 9 treated animals). Total phosphorylase activity had increased from $125 \pm 6.5$ to $194 \pm 6.6$. However, when calculated on a per uterus basis, phosphorylase $a$ increased from 14.6 in the controls to 34.4 in the treated animals, while total activity actually decreascd slightly from $62 \cdot 8$ to $58 \cdot 5$. This was due to the fact that uteri from rats injected with this large dose of epinephrine weighed only about $60 \%$ as much as did control uteri, when frozen immediately without blotting the tissues. This in turn probably resulted from the decrease in vascularity and fluid content of these uteri.

The effects of varying doses of epinephrine on uterine phosphorylase activation are shown in Fig. 2. In this figure the dose is plotted on a logarithmic scale against the

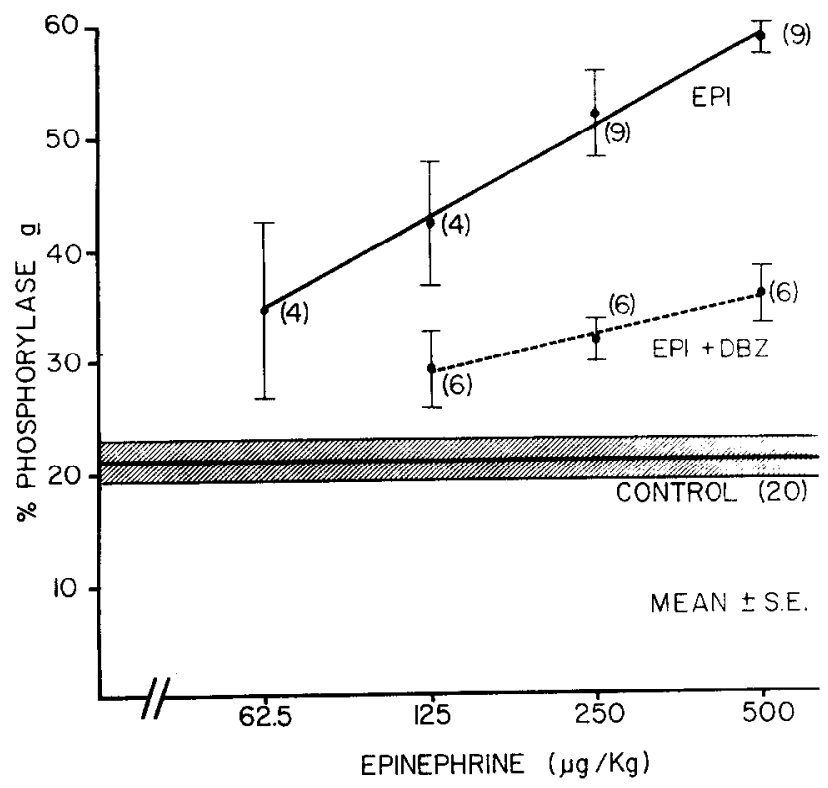

FIG. 2. Dose-response curves for the activation of uterine phosphorylase by epinephrine. Uteri were excised $5 \mathrm{~min}$ after the i.p. injection of epinephrine. The upper curve (EPI) shows the effect of epinephrine in normal animals; the lower curve (EPI + DBZ) illustrates the effect of epinephrine in animals pretreated for $2-3 \mathrm{hr}$ with phenoxybenzamine $(7 \mathrm{mg} / \mathrm{kg}$ i.p.).

response on an arithmetic scale. Such a plot yields a linear relationship. When the same doses of epinephrine were administered to animals pretreated with phenoxybenzamine, a much shallower dose-response curve was obtained.

Effects of epinephrine on uterine phosphorylase activity in ovariectomized and estrogenprimed rats

Since Leonard had observed only decreases in uterine phosphorylase activity after administration of epinephrine to ovariectomized or estrogen-primed animals, it was of interest to determine whether these procedures would result in a response qualitatively different from that which we had obtained in normal animals. A group of animals was ovariectomized and after a recovery period of 2-3 weeks they were 
injected i.p. with $500 \mu \mathrm{g}$ epinephrine $/ \mathrm{kg}$ and sacrificed at varying time intervals. An increase in phosphorylase $a$ activity was observed, similar to that seen in normal animals, although of lesser magnitude (Table 1).

A second group of ovariectomized animals received s.c. injections of $50 \mu \mathrm{g}$ estradiol benzoate in peanut oil. After $48 \mathrm{hr}$ they were injected i.p. with varying doses of epinephrine and sacrificed $5 \mathrm{~min}$ later. It can be seen from the data in Table 2 that the

TABLE 1. EFFECT OF EPINEPHRINE ON UTERINE PHOSPHORYLASE ACTIVITY IN OVARIECTOMIZED RATS

\begin{tabular}{ccc}
\hline $\begin{array}{c}\text { Time after injection } \\
\text { (min) }\end{array}$ & N & $\begin{array}{c}\text { \% Phosphorylase } a \\
\text { (mean } \pm \text { S.E.) }\end{array}$ \\
\hline $\begin{array}{c}\text { Control } \\
5\end{array}$ & 8 & $27 \cdot 7 \pm 2 \cdot 6$ \\
10 & 4 & $43 \cdot 7 \pm 3 \cdot 8^{*}$ \\
30 & 4 & $40 \cdot 5 \pm 5 \cdot 5$ \\
& 2 & $34 \cdot 4,31 \cdot 6$ \\
\hline
\end{tabular}

All animals received $500 \mu \mathrm{g}$ epinephrine $/ \mathrm{kg}$, i.p.

* Significantly different from controls $(\mathbf{P}<0.01)$.

TABLE 2. EFFECT OF EPINEPHRINE ON UTERINE PHOSPHORYLASE ACTIVITY IN ESTROGENPRIMED RATS

\begin{tabular}{lcc}
\hline \multicolumn{1}{c}{ Treatment } & N & $\begin{array}{c}\% \text { Phosphorylase } a \\
\text { (mean } \pm \text { S.E.) }\end{array}$ \\
\hline Estrogen-primed controls & 7 & $33 \cdot 7 \pm 1 \cdot 8$ \\
Estrogen $+125 \mu \mathrm{g} \mathrm{epi./kg}$ & 4 & $39 \cdot 6 \pm 3 \cdot 7$ \\
Estrogen $+250 \mu \mathrm{g} \mathrm{epi./kg}$ & 5 & $51 \cdot 5 \pm 1 \cdot 8^{*}$ \\
Estrogen $+500 \mu \mathrm{g} \mathrm{epi.} / \mathrm{kg}$ & 4 & $47 \cdot 7 \pm 1 \cdot 7^{*}$ \\
\hline
\end{tabular}

All animals sacrificed 5 mins after epinephrine injections.

* Significantly different from estrogen alone $(P<0.001)$.

per cent phosphorylase $a$ levels are almost identical with those seen after similar doses of epinephrine in normal animals, with the exception of the dose of $500 \mu \mathrm{g} / \mathrm{kg}$, which produced less activation in the estrogen-primed animals than in the normals. It is also apparent that the administration of estradiol itself raised the levels of phosphorylase $a$ above the levels previously noted for untreated ovariectomized animals, although the increase was not statistically significant. Furthermore, per cent phosphorylase $a$ levels in ovariectomized estrogen-primed rats were significantly higher $(P<0.01)$ than the levels in any of the groups of normal untreated animals (which averaged from $20.0 \pm$ $1 \cdot 2$ to $23 \cdot 1 \pm 1 \cdot 7$ ).

Within $48 \mathrm{hr}$ after the administration of estradiol to ovariectomized animals, the uterine weights had increased markedly. The increases in size and weight were accompanied by hyperemia, hydration, and softness of the tissue and by corresponding increases in the total phosphorylase activity per uterus. 
The influence of adrenergic blockade on catecholamine-induced activation of uterine phosphorylase

Figure 3 illustrates the effects of several adrenergic blocking agents on the phosphorylase activation induced by two different doses of epinephrine. Normal animals were used throughout these and subsequent experiments.

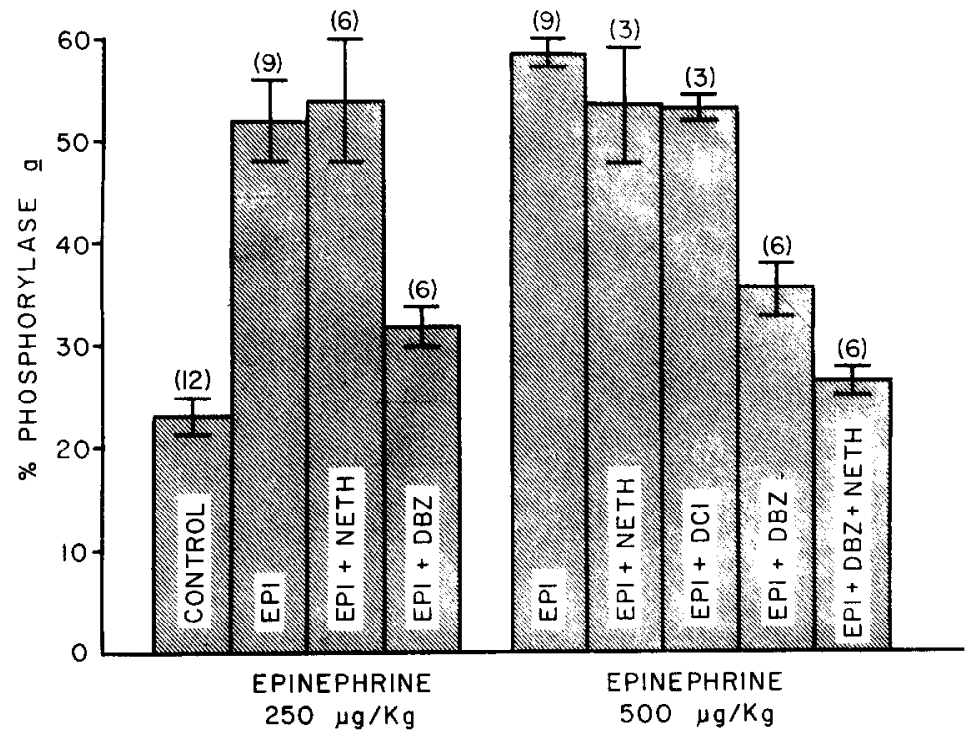

FIG. 3. Effect of adrenergic blocking agents on uterine phosphorylase activation by epinephrine (EPI). Uteri were excised $5 \mathrm{~min}$ after the injection of epinephrine. Nethalide (NETH, $25 \mathrm{mg} / \mathrm{kg}$ ) and DCI $(10 \mathrm{mg} / \mathrm{kg})$ were injected s.c. $30 \mathrm{~min}$ before epinephrine administration. Phenoxybenzamine

(DBZ) was administered i.p. in a dose of $7 \mathrm{mg} / \mathrm{kg}, 2-3 \mathrm{hr}$ prior to epinephrine injections.

Pretreatment of animals with phenoxybenzamine $(7 \mathrm{mg} / \mathrm{kg}$ i.p., $2-3 \mathrm{hr}$ before epinephrine injections) partially blocked the epinephrine-induced activation of uterine phosphorylase, whereas DCI ( $10 \mathrm{mg} / \mathrm{kg} \mathrm{s.c.}, 30 \mathrm{~min}$ before epinephrine) or nethalide $(25 \mathrm{mg} / \mathrm{kg}$ similarly injected) produced no significant blockade of the response. Pretreatment with both phenoxybenzamine and nethalide resulted in a response to epinephrine significantly lower than that seen after pretreatment with phenoxybenzamine alone $(P<0.02)$. Neither phenoxybenzamine nor nethalide alone altered phosphorylase $a$ levels in control animals.

The i.p. administration of norepinephrine $(250 \mu \mathrm{g} / \mathrm{kg})$ or isoproterenol $(100 \mu \mathrm{g} / \mathrm{kg})$ produced significant activation of uterine phosphorylase $(P<0.001)$. This is shown in Fig. 4. Prior administration of phenoxybenzamine completely blocked the response to norepinephrine but did not alter the response seen after isoproterenol. On the other hand, the response to isoproterenol was significantly decreased $(P<0.01)$ by pretreatment with nethalide, a procedure which did not alter the response to norepinephrine.

\section{Effect of stagnant anoxia on uterine phosphorylase activity}

A marked constriction of the uterine vasculature was observed in animals which had received intraperitoneal injections of epinephrine or norepinephrine. This 
vascoconstriction was abolished by pretreating the animals with phenoxybenzamine. Since pretreatment with phenoxybenzamine also markedly decreased the phosphorylase activation seen after these drugs, it was conceivable that the vascoconstriction and subsequent tissue anoxia were contributing to the observed increases in phosphorylase activity. Therefore, a series of experiments was performed in which the

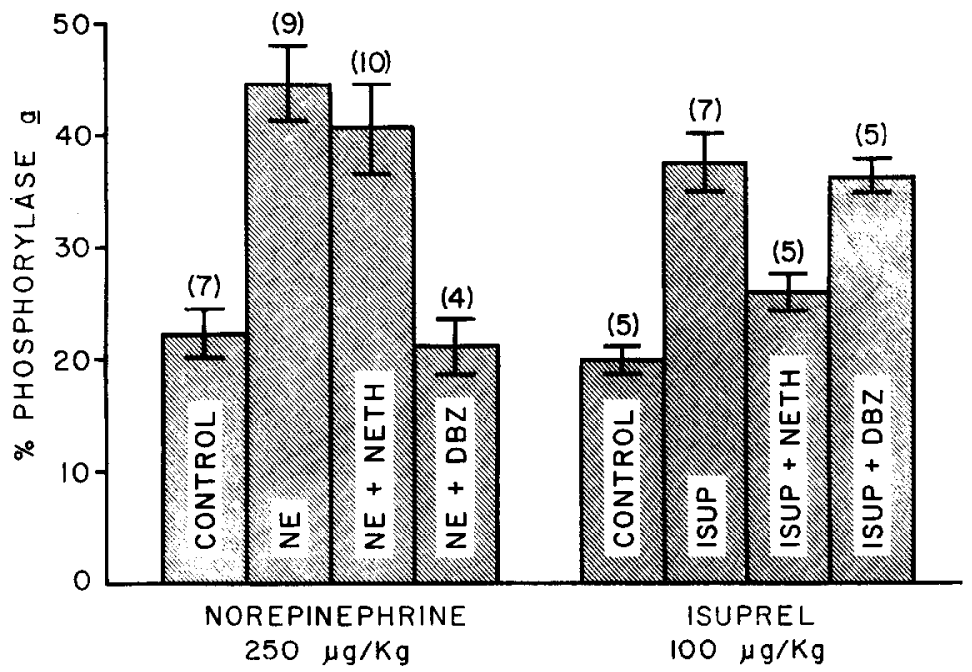

Fig. 4. Effect of adrenergic blocking agents on uterine phosphorylase activation by norepinephrine (NE) and isoproterenol (Isuprel, ISUP). Uteri were excised $5 \mathrm{~min}$ after catecholamine injections.

Nethalide (NETH) and phenoxybenzamine (DBZ) were administered as in Fig. 3.

uterine blood vessels at both ends of one uterine horn were ligated for $5 \mathrm{~min}$ and a segment of that horn removed and assayed for phosphorylase. The opposite horn of the same uterus was similarly manipulated, but the vessels were not ligated, and a portion of this horn was removed for estimation of control phosphorylase activity. The data in Table 3 show that phosphorylase $a$ activity could be markedly increased by ligation of the uterine blood vessels for $5 \mathrm{~min}$.

TABLE 3. EFFECT OF LIGATION OF UTERINE VESSELS ON UTERINE PHOSPHORYLASE ACTIVITY

\begin{tabular}{ccc}
\hline Treatment & N & $\begin{array}{c}\% \text { Phosphorylase } a \\
\text { (mean } \pm \text { S.E.) }\end{array}$ \\
\hline Control & 9 & $24 \cdot 4 \pm 1.6$ \\
Uterine vessels ligated for 5 min & 8 & $44.1 \pm 2 \cdot 5^{*}$ \\
\hline
\end{tabular}

* Significantly different from controls $(P<0.001)$.

\section{Effect of intravenous infusion of epinephrine on uterine phosphorylase activity}

It was of interest to determine whether epinephrine was capable of activating uterine phosphorylase when administered by other than the intraperitoneal route. Leonard has reported that epinephrine does not affect utcrine phosphorylase activity when administered subcutaneously, even in large doses. ${ }^{10,17,18}$ Similarly, Hornbrook and Brody have noted that subcutaneous injections of epinephrine do not activate cardiac muscle phosphorylase unless the animals are pretreated with phenoxybenzamine..$^{5}$ Apparently, intense vascoconstriction at the site of injection prevents rapid 
uptake of the drug by the systemic circulation. Therefore, a number of animals received varying doses of epinephrine by intravenous infusion into an external jugular vein, as previously described. ${ }^{5}$ The results are shown in Table 4 . It is apparent that uterine phosphorylase can be activated by intravenous infusion of epinephrine, although the maximal activation attained is considerably less than that seen after intraperitoneal injections of the drug. Increasing the rate of infusion beyond $2.0 \mu \mathrm{g} /$ $\mathrm{kg} / \mathrm{min}$ produced no further activation of phosphorylase.

TABLE 4. EFFECT OF INTRAVENOUS INFUSION OF EPINEPHRINE ON UTERINE PHOSPHORYLASE ACTIVITY

\begin{tabular}{lcc}
\hline Treatment & N & $\begin{array}{c}\% \text { Phosphorylase } a \\
\text { (mean } \pm \text { S.E.) }\end{array}$ \\
\hline Saline infusion & 7 & $18.0 \pm 3.2$ \\
Epi., $1.0 \mu \mathrm{g} / \mathrm{kg} / \mathrm{min}$ & 4 & $29.0 \pm 4 \cdot 2$ \\
Epi., $2 \cdot 0 \mu \mathrm{g} / \mathrm{kg} / \mathrm{min}$ & 4 & $36.2 \pm 2.9^{*}$ \\
Epi., $4.0 \mu \mathrm{g} / \mathrm{kg} / \mathrm{min}$ & 4 & $37.8 \pm \mathbf{0}^{\circ} \dagger$ \\
Epi., $8 \cdot 0 \mu \mathrm{g} / \mathrm{kg} / \mathrm{min}$ & 4 & $32.5 \pm 2 \cdot 2^{*}$
\end{tabular}

Animals were infused for $5 \mathrm{~min}$ at the rates indicated in the table.

* Significantly different from controls $(P<001)$.

$\dagger$ Significantly different from controls $(P<0.001)$.

\section{DISCUSSION}

The changes observed in uterine phosphorylase activity and glycogen levels after epinephrine administration are similar to those previously observed in this laboratory for heart and skeletal muscle. ${ }^{5}$ The phosphorylase data are not in agreement with those reported by Leonard, who observed only decreases in uterine phosphorylase activity after administration of identical doses of epinephrine. ${ }^{10,11} \mathrm{It}$ is difficult to compare many of our results with those cited above, since no experiments were reported on untreated control or ovariectomized animals at times less than $1 \mathrm{hr}$ after epinephrine administration. However, decreases in uterine phosphorylase $a$ activity were reported $5 \mathrm{~min}$ after administration of epinephrine to estrogen-primed animals. In our experiments, at this time after drug administration, phosphorylase $a$ levels are markedly elevated. We are at present unable to explain the discrepancies between our results and those previously described above. In a more recent report, significant activation of phosphorylase $a$ has been demonstrated in isolated uterine segments exposed to epinephrine for $2 \mathrm{~min}^{8}$ Therefore, although the results of our in vivo experiments do not concur with those of Leonard, they do tend to support the recent in vitro findings from that laboratory. Earlier studies in the literature have indicated that epinephrine does not activate phosphorylase in the isolated rat uterus, ${ }^{3}$ but no experimental data were included with these reports.

The decreases observed in the glycogen content of the uterus after intraperitoneal injections of epinephrine are similar to those previously described, ${ }^{10,11}$ although they appear to be of somewhat shorter duration. The maximal decreases reported above occurred $1 \mathrm{hr}$ after administration of epinephrine, whereas in our experiments maximal decreases were seen $30 \mathrm{~min}$ after injection and had begun to return toward normal within $1 \mathrm{hr}$. No glycogen determinations were carried out by us at times greater than $1 \mathrm{hr}$ after epinephrine administration, and further comparison is not possible. 
Simultaneous increases in phosphorylase activity and glycogen content of rat uterus after injections of estradiol have been demonstrated by Leonard ${ }^{10,11}$ and by Bo, who used histochemical techniques. ${ }^{19}$ The ability of estrogen treatment to elevate uterine glycogen levels had been previously reported. ${ }^{18,20,21}$ The present results tend to support these earlier observations with respect to the increased phosphorylase $a$ levels after estrogen. Not only was per cent phosphorylase $a$ elevated, but total phosphorylase activity per uterus also increased. It seems likely that the gradual, sustained increase in phosphorylase $a$ activity seen after estrogen treatment is different in nature from the more marked, acute activation produced by epinephrine administration. The former is accompanied not only by increases in glycogen but by general proliferative changes in the uterus, including increases in weight, hydration, total phosphorylase activity, and activity of other enzymes as well. ${ }^{22}$ The observation that glycogen levels increase in the face of increased phosphorylase activity after estrogen seems contradictory if we accept the hypothesis that phosphorylase activation promotes glycogenolysis in vivo. A possible explanation may lie in the observation by Gorski and Mueller that estradiol administration in rats produces substantial increases in uterine content of UTP, UDPG, and UDPAG. ${ }^{23}$ The UDPG-transglycolase pathway has been suggested as being the normal pathway for glycogen synthesis in vivo, and it is conceivable that estrogen-induced activation of this pathway might result in increased glycogen deposition in the uterus in spite of moderate increases in phosphorylase activity. Bo has suggested teleologically that the enzyme activity in the uterus may be elevated after estrogen stimulation in order to break down the polysaccharide. 19

Rudzik and Miller have demonstrated that the concentration of epinephrine in the rat uterus during estrus is twice that found during diestrus. ${ }^{24}$ This was later confirmed by Wurtman et al., who further reported that the uptake and retention of exogenous epinephrine by rat uterus was greater during estrus than during diestrus. ${ }^{25}$ These findings may be related not only to the increased levels of phosphorylase $a$ seen after estradiol administration but also to the decreased sensitivity of uterine phosphorylase to exogenous epinephrine, which has been observed in ovariectomized rats. ${ }^{8}$

The classification of the uterine phosphorylase response to catecholamines as either an $a$ - or $\beta$ - or perhaps as both an $a$ - and $\beta$-adrenergic receptor is somewhat difficult on the basis of in vivo studies. $\dagger$ The ability of norepinephrine to stimulate phosphorylase activity is an indication that $a$-adrenergic receptors are involved, since norepinephrine is considered to be primarily a-adrenergic in action. This is further substantiated by the observation that this response is completely abolished by the $a$-adrenergic blocking agent, phenoxybenzamine, but is not affected by the $\beta$-blocking agent, nethalide. However, it is apparent that $a$-adrenergic receptors are also involved, as indicated by the ability of isoproterenol to stimulate uterine phosphorylase $a$ activity and the blockade of this effect by nethalide, but not by phenoxybenzamine. Furthermore, the effects of epinephrine, which is assumed to possess both $a$ - and $\beta$ adrenergic activity, were more completely blocked by pretreatment with both phenoxybenzamine and nethalide than by pretreatment with either agent alone. These observations indicate that activation of uterine phosphorylase may be accomplished by

\footnotetext{
$\dagger$ The terms $\alpha$ - and $\beta$-receptor are used in the connotation originally proposed by Ahlquist (Amer. J. Physiol. 153, 586, 1948).

B-B.P.
} 
stimulation of either $\alpha$ - or $\beta$-receptors. However, there is some indication that the $\alpha$ effect is an indirect one, resulting from stimulation of $\alpha$-receptors in the blood vessels supplying the uterus, rather than upon the uterine smooth muscle itself. The route of catecholamine administration used in the above experiments allows high concentrations of the drugs to accumulate at these sites, and the resulting intense vascoconstriction, which can be observed grossly, may produce sufficient tissue anoxia to activate uterine phosphorylase. This concept is supported by the observation that ligation of the uterine vessels for $5 \mathrm{~min}$ resulted in a marked activation of phosphorylase in the anoxic segment of the uterus. It should be noted that the $\alpha$ components of the responses to $250 \mu \mathrm{g}$ and $500 \mu \mathrm{g}$ epinephrine $/ \mathrm{kg}$ (i.e. those portions of the responses blocked by phenoxybenzamine), as well as the response to $250 \mu \mathrm{g}$ norepinephrine $/ \mathrm{kg}$, are of the same magnitude as the increases produced by ligation of the uterine blood vessels. These results are not in agreement with those of Leonard, ${ }^{11}$ who reported slight decreases in phosphorylase $a$ in the uteri of estrogen-primed rats after ligation of the uterine vessels for $10 \mathrm{~min}$. However, they are consistent with the findings of Parmeggiani and Morgan, ${ }^{26}$ who observed substantial increases in per cent phosphorylase $a$ in isolated hearts exposed to anoxia for $2 \mathrm{~min}$.

The significance of the effects of catecholamines on phosphorylase activity in the uterus, with respect to their actions on uterine motility and tone, remains to be determined.

Acknowledgements - The authors wish to acknowledge the excellent technical assistance of Lawrencc Carr and John McNeill.

\section{REFERENCES}

1. S. Ellis, Pharmacol. Rev. 8, 485 (1956).

2. D. W. Stetten and M. R. Stetten, Physiol. Rev. 40, 505 (1960).

3. E. W. Sutherland and T. W. Rall, Pharmacol. Rev. 12, 265 (1960).

4. E. W. Sutherland, in Phosphorus Metabolism, Vol. 2, W. D. McElroy and B. Glass, Eds. Johns Hopkins Press, Baltimore (1952).

5. K. R. HORNBROOK and T. M. BRODY, J. Pharmacol. exp. Ther. 140, 295 (1963).

6, K. R. Horndrook and T. M. Brody, Biochem. Pharmacol. 12, 1407 (1963).

7. S. Ellis, J. McGill and H. L. ANDerson, Fed. Proc. 16, 294 (1957).

8. S. L. LEONARD and M. CRANDALL, Endocrinology 73, 807 (1963).

9. E. Bueding, E. Bulbring, H. Kuriyama and G. Gercken, Nature (Lond.) 196, 944 (1962).

10. S. L. LeONARD, Endocrinology 63, 853 (1958).

11. S. L. LEONARD, Endocrinology 71, 803 (1962).

12. W. Z. Hassid and S. Abram, in Methods in Enzymology, Vol. 3, S. P. ColowiCK and N. O. KaPLAN, Eds. Academic Press, New York (1957).

13. S. Seifler, S. Dayton, B. Novic and E. Muntwyler, Arch. Biochem. 25, 191 (1950).

14. G. T. CoRI and C. F. CoRI, J. biol. Chem. 135, 733 (1940).

15. C. H. Fiske and Y. SubBaRow, J. biol. Chem. 66, 375 (1925).

16. G. T. CoRi, B. Illingworth and P. J. Keller, in Methods in Enzymology, Vol. 1 (1955).

17. J. N. COOCH and S. L. Leonard, Endocrinology 65, 135 (1959).

18. J. L. KostYo and S. L. LeONARD, Endocrinology 56, 616 (1955).

19. W. J. Bo, J. Histochem. Cytochem. 9, 430 (1961).

20. E. G. BoetTiger, J. cell. comp. Physiol. 27, 9 (1946).

21. O. WalaAs, Acta endocr. (Kbh.) 10, 175 (1952).

22. D. B. M. ScotT and A. G. LisI, Biochem. J. 77, 52 (1960).

23. J. GORSKI and G. C. MUELleR, Arch. Biochem. 102, 21 (1963).

24. A. D Rudzik and J. W. Miller, J. Pharmacol. exp. Ther. 138, 88 (1962).

25. R. J. Wurtman, E. W. ChU and J. AXelrod, Nature (Lond.) 198, 547 (1963).

26. A. Parmeggiani and H. E. Morgan, Biochem. biophys. Res. Commun. 9, 252 (1962). 